\title{
Prognostic significance of advanced age in patients with intrahepatic cholangiocarcinoma: A retrospective study of the SEER database.
}

\author{
Zheng Wang*, Xiang-Yu Wang", Jian-Hua Li", Xin Yang, Wen-Wei Zhu \\ Department of General Surgery, Institutes of Cancer Metastasis, Huashan Hospital, Fudan University, Shanghai, China \\ ${ }^{\#}$ These authors have equally contributed to this study.
}

\begin{abstract}
This study analyzed the prognostic significance of age in patients with intrahepatic cholangiocarcinoma (ICC). Cases diagnosed with ICC between 1988 and 2009 were extracted from the Surveillance, Epidemiology and End Results (SEER) database as the primary cohort. The enrolled patients were divided into 2 groups: the elderly group ( $\geq 65 \mathrm{y}$ of age) and young group ( $<65 \mathrm{y}$ of age). The 1,3 and 5-y cancer-specific survival (CSS) rates were obtained. Kaplan-Meier curves were applied and multivariable Cox regression models were built to analyze the risk factors for prognosis. A multifactorial, integrative nomogram for prognostic prediction was formulated by software $R$. Cases diagnosed in 2010 from the SEER database were enrolled as the validation cohort. In total, 2161 patients were ultimately included in the primary cohort. The 1,3 and $5-y$ CSS rates were $34.3 \%, 12.5 \%$ and $6.5 \%$ in the elderly group and $49.8 \%, 21.3 \%$ and $11.5 \%$ in the young group, respectively. Univariate $(P=0.001)$ and multivariate $(\mathrm{P}<0.001)$ analysis revealed a significant difference in CSS between the two groups. Clinical variables including age, pathological grade, primary tumor stage, lymph node invasion and metastasis were integrated to formulate the nomogram for prognostic prediction, and its predictive power was higher than that of conventional TNM staging. The results were confirmed in the validation cohort. In conclusion, aging could provide important prognostic information for ICC patients and further serve as a critical stratification parameter for the choice of treatment.
\end{abstract}

Keywords: Intrahepatic cholangiocarcinoma, Elderly, Prognosis, Nomogram, SEER.

Accepted on April 25, 2018

\section{Introduction}

Intrahepatic cholangiocarcinoma (ICC) is the second most common primary liver cancer after hepatocellular carcinoma (HCC) $[1,2]$. During the past three decades, its incidence and mortality have increased rapidly worldwide [3]. Clinically, hepatectomy remains the cornerstone of the curative treatment for this fatal malignancy [4].

However, only a few patients can survive long-term after diagnosis because of a high probability of loco-regional recurrence and distant metastasis [5]. Based on critical clinical parameters such as tumor number, vascular invasion and lymph node status, the $7^{\text {th }}$ American Joint Committee on Cancer (AJCC) staging system is currently used for ICC clinical staging and prognostic evaluation.

Circulating biomarkers such as carbohydrate antigen (CA) 19-9 and carcinoembryonic antigen levels should also be considered for predicting ICC outcome [6]. However, due to their relative rarity, other parameters clinically applicable for ICC prognostic prediction are still lacking and require further exploration.
Compared to HCC, ICC shows distinct etiological features; one of which is that it occurs more commonly in elderly patients and age $>65 \mathrm{y}$ is considered a general risk factor for cholangiocarcinoma [7,8]. Aging plays a vital role in the initiation and progression of cancer development [9].

In recent years, several large cohort investigations have reported the potential link between aging and ICC [10-12]. However, an explicit correlation between aging and prognosis remains to be clarified. On this point, most of the previous studies were limited by small sample sizes or they did not adjust for potential confounding factors [13-18].

Additionally, those studies merely focused on patients receiving hepatic surgery, but they did not consider the nonoperative group when analyzing the prognostic significance of age. In consideration of the low resectability of ICC, especially in elderly patients, the impact of aging on clinical outcome merits further investigation in large cohorts.

In this study, we used data from the Surveillance, Epidemiology and End Results (SEER) database to analyze the prognostic value of age in ICC patients while controlling for background diseases and other confounding factors. 


\section{Materials and Methods}

\section{Patients}

This was a retrospective observational study using the SEER cancer database. The current SEER database represents 18 population-based cancer registries in the USA. This database contains no personal identifiers and produces public-use data for cancer studies. The National Cancer Institute SEER*Stat software (version 8.3.2, http://seer.cancer.gov/seerstat) was used to access the SEER database.

The primary cohort was limited to cases diagnosed with ICC between 1988 and 2009 because data for the AJCC staging system were not provided before 1988. Patients diagnosed in 2010 were enrolled as the validation cohort. To ensure an adequate follow-up time, we excluded cases diagnosed after 2010. To identify ICC patients, we used the International Classification of Diseases for Oncology ( $3^{\text {rd }}$ edition, ICD-O-3) site recode for the liver (22.0) with the histology code for cholangiocarcinoma (8160), and the site recode for the intrahepatic bile duct (22.1) with histology codes for malignant neoplasm (8000), malignant tumor cells (8001), carcinoma (8010), undifferentiated carcinoma (8020), adenocarcinoma (8140), and cholangiocarcinoma (8160). Exclusion criteria were as follows: HCC, hilar cholangiocarcinoma, extra-hepatic cholangiocarcinoma, gallbladder carcinoma, metastatic adenocarcinoma, incomplete TNM staging, and age $<18 \mathrm{y}$.

\section{Follow-up and survival}

The date of last follow-up was defined as the last date the patient was contacted by the hospital or seen by the doctor, or the date of death. The primary endpoint was cancer-specific survival (CSS), which was calculated from the date of diagnosis to the date of cancer-specific death. Deaths attributed to ICC were defined as events, and deaths attributed to other causes were considered as censored data. To investigate the short-term and long-term survival outcomes, 1, 3 and 5-y CSS was calculated.

\section{Ethics statement}

This research was based on the publicly available data from the SEER database and the data-use agreement was assigned the reference number 12945-Nov2016. Patients' informed consent was not required because no direct interaction with patients was performed and there was no personal identification. This research was conducted in compliance with the Declaration of Helsinki and approved by the Institutional Review Board of Huashan Hospital, Fudan University, and Shanghai, China.

\section{Statistical analysis}

Variables including age, gender, race, pathological grade, primary tumor stage, lymph node invasion and metastasis were extracted from the SEER database. All patients were restaged according to the AJCC Cancer Staging Manual ( $7^{\text {th }}$ Edition, 2010). Patients diagnosed with ICC were divided into two subgroups according to age: group A ( $\geq 65 \mathrm{y}$ of age) and group $\mathrm{B}$ ( $<65 \mathrm{y}$ of age).

We used SPSS version 19.0 (SPSS Inc., Chicago, IL, USA) to conduct the statistical analyses. $\chi^{2}$ tests were used to analyze the correlation of age (elderly and young) with other clinicopathological features. Kaplan-Meier methods were used to generate survival curves, and univariate analyses were performed by log-rank tests between the two groups. Multivariate Cox regression models were applied to analyze risk factors for survival outcomes. All tests were two-sided and $\mathrm{P}<0.05$ indicated statistical significance.

\section{Construction and validation of the nomogram}

Based on the results of multivariate Cox regression analysis, a nomogram was generated by statistical computing software $\mathrm{R}$ version 3.3.1 (https://www.r-project.org/) with the RMS package. A final model selection was conducted using a backward step-down process in accordance with the Akaike information criterion [19].

One thousand bootstrap resamples were applied to calculate the concordance index (C-index) and formulate the calibration curves, which assessed the performance of the nomogram [20]. Comparison between the established nomogram and conventional tumor staging system (AJCC 7th edition staging) was performed by the C-index [21]. A larger C-index implied a more accurate predictive model for prognosis [6]. Calibration curves were conducted by comparing nomogram-predicted survival with observed survival both in the primary and validation cohorts.

\section{Results}

\section{Patient characteristics}

In the primary cohort, a total of 2161 eligible patients with ICC in the SEER database were identified during the 21-y period (1988-2009), which included 1202 cases (55.6\%) in group A and $959(44.4 \%)$ in group B. No significant difference was shown in main demographic and clinical variables between groups A and B. Additionally, 414 patients were ultimately included in the validation cohort. Patients' characteristics are summarized in Table 1.

Table 1. Characteristics of ICC patients from SEER database.

\begin{tabular}{lllll}
\hline \multirow{2}{*}{ Characteristics } & \multicolumn{3}{c}{ Primary cohort $(\mathrm{n}=2161)$} & $\begin{array}{l}\text { Validation } \\
\text { cohort } \\
(\mathrm{n}=414)\end{array}$ \\
\cline { 2 - 4 } & $\begin{array}{l}\text { Age } \geq 65 \\
(\mathrm{n}=1202)\end{array}$ & $\begin{array}{l}\text { Age<65 } \\
(\mathrm{n}=959)\end{array}$ & P value \\
\hline Gender & \multicolumn{3}{c}{0.081} \\
\hline Male & 590 & 507 & 202 \\
\hline Female & 612 & 452 & 212 \\
\hline Race & & & 0.073 \\
\hline
\end{tabular}


Prognostic significance of advanced age in patients with intrahepatic cholangiocarcinoma: A retrospective study of the SEER database

\begin{tabular}{|c|c|c|c|}
\hline Caucasian & 951 & 732 & 312 \\
\hline Black & 79 & 88 & 38 \\
\hline Others ${ }^{*}$ & 172 & 139 & 64 \\
\hline Pathological grade & & & \\
\hline High & 64 & 63 & 16 \\
\hline Moderate & 261 & 205 & 96 \\
\hline Poor & 220 & 205 & 66 \\
\hline Un-differentiation & 9 & 10 & 3 \\
\hline Unknown & 648 & 476 & 233 \\
\hline Primary tumor stage & & & \\
\hline T1 & 562 & 457 & 171 \\
\hline T2 & 164 & 101 & 154 \\
\hline T3 & 304 & 241 & 54 \\
\hline $\mathrm{T} 4$ & 172 & 160 & 35 \\
\hline Lymph node invasion & & & \\
\hline Yes & 313 & 260 & 110 \\
\hline No & 889 & 699 & 304 \\
\hline Metastasis & & & \\
\hline Yes & 372 & 264 & 121 \\
\hline No & 830 & 695 & 293 \\
\hline AJCC stage & & & \\
\hline I & 358 & 242 & 118 \\
\hline II & 287 & 227 & 81 \\
\hline III & 85 & 68 & 25 \\
\hline IV & 472 & 422 & 190 \\
\hline Surgery & & & \\
\hline Yes & 307 & 251 & 126 \\
\hline No & 895 & 708 & 288 \\
\hline Radiation & & & \\
\hline
\end{tabular}

\begin{tabular}{llll}
\hline Yes & 241 & 186 & 59 \\
\hline No & 961 & 773 & 355 \\
\hline
\end{tabular}

Note: ICC: Intrahepatic Cholangiocarcinoma; AJCC: American Joint Committee on Cancer; "Including American Indian, AK Native, Asian, Pacific Islander and unknowns.

\section{Impact of age on short and long-term survival}

The 1 and 3-y CSS rates were $34.3 \%$ and $12.5 \%$ in group A and $49.8 \%$ and $21.3 \%$ in group $\mathrm{B}$, respectively, which indicated a significant difference $(\mathrm{P}<0.001$, Table 2$)$. The 5-y CSS rate was $6.5 \%$ in group $\mathrm{A}$ and $11.5 \%$ in group $\mathrm{B}$, which also showed a significant difference $(\mathrm{P}=0.001$ and Figure 1$)$.

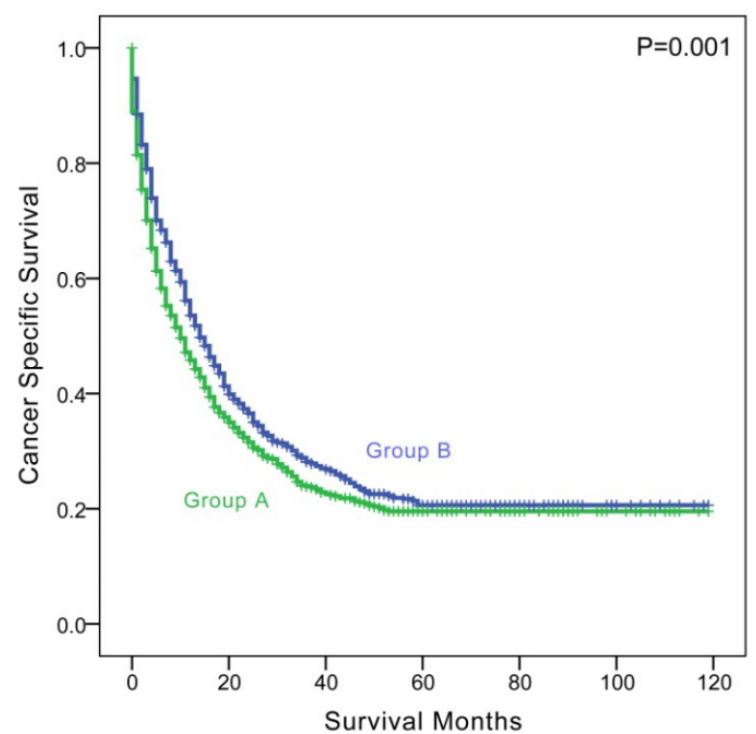

Figure 1. Survival curves in the primary cohort according to age status. Group A: age $\geq 65$; Group B: age $<65$. Group A vs. Group B, $\chi^{2}=10.422, P=0.001$.

Based on univariate analysis, pathological grade $(\mathrm{P}<0.001)$, primary tumor stage $(\mathrm{P}<0.001)$, lymph node invasion $(\mathrm{P}=0.001)$, metastasis $(\mathrm{P}<0.001)$ and AJCC stage $(\mathrm{P}<0.001)$ were considered significant risk factors for patient survival in ICC (Table 2). However, prognostic factors did not include surgery $(\mathrm{P}=0.062)$ or radiation $(\mathrm{P}=0.731)$.

Table 2. Univariate survival analysis of various clinical variables for cancer specific survival in the primary cohort.

\begin{tabular}{|c|c|c|c|c|c|c|}
\hline \multirow{2}{*}{ Variable } & \multicolumn{2}{|l|}{ 1-y CSS } & \multicolumn{2}{|l|}{$3-y$ CSS } & \multicolumn{2}{|l|}{ 5-y CSS } \\
\hline & Rate (\%) & $P$ value & Rate (\%) & $P$ value & Rate (\%) & $P$ value \\
\hline Gender & & 0.039 & & 0.12 & & 0.209 \\
\hline Male & 0.386 & & 0.145 & & 0.076 & \\
\hline Female & 0.439 & & 0.183 & & 0.099 & \\
\hline Age & & $<0.001$ & & $<0.001$ & & 0.001 \\
\hline$\geq 65$ & 0.343 & & 0.125 & & 0.065 & \\
\hline$<65$ & 0.498 & & 0.213 & & 0.115 & \\
\hline
\end{tabular}




\begin{tabular}{|c|c|c|c|c|c|c|}
\hline Race & & 0.142 & & 0.454 & & 0.553 \\
\hline Caucasian & 0.417 & & 0.159 & & 0.083 & \\
\hline Black & 0.383 & & 0.178 & & 0.102 & \\
\hline Others* & 0.399 & & 0.183 & & 0.103 & \\
\hline Pathological grade & & $<0.001$ & & $<0.001$ & & $<0.001$ \\
\hline High/moderate & 0.583 & & 0.291 & & 0.165 & \\
\hline Poor/un-differentiation & 0.417 & & 0.137 & & 0.063 & \\
\hline Unknown & 0.307 & & 0.099 & & 0.05 & \\
\hline Primary tumor stage & & $<0.001$ & & $<0.001$ & & $<0.001$ \\
\hline T1-2 & 0.458 & & 0.218 & & 0.119 & \\
\hline T3-4 & 0.351 & & 0.092 & & 0.044 & \\
\hline Lymph node invasion & & 0.292 & & $<0.001$ & & 0.001 \\
\hline Yes & 0.395 & & 0.08 & & 0.021 & \\
\hline No & 0.416 & & 0.187 & & 0.105 & \\
\hline Metastasis & & $<0.001$ & & $<0.001$ & & $<0.001$ \\
\hline Yes & 0.222 & & 0.043 & & 0.015 & \\
\hline No & 0.474 & & 0.204 & & 0.111 & \\
\hline AJCC stage & & $<0.001$ & & $<0.001$ & & $<0.001$ \\
\hline I & 0.492 & & 0.271 & & 0.156 & \\
\hline II & 0.488 & & 0.198 & & 0.113 & \\
\hline III & 0.346 & & 0.124 & & 0.072 & \\
\hline IV & 0.313 & & 0.065 & & 0.019 & \\
\hline Surgery & & 0.095 & & 0.075 & & 0.062 \\
\hline Yes & 0.392 & & 0.153 & & 0.073 & \\
\hline No & 0.42 & & 0.168 & & 0.093 & \\
\hline Radiation & & 0.464 & & 0.914 & & 0.731 \\
\hline Yes & 0.398 & & 0.174 & & 0.122 & \\
\hline No & 0.414 & & 0.162 & & 0.081 & \\
\hline
\end{tabular}

Note: ICC: Intrahepatic Cholangiocarcinoma; AJCC: American Joint Committee on Cancer; "Including American Indian, AK Native, Asian, Pacific Islander and unknowns.

Multivariate Cox regression models were built to evaluate the significant risk factors for survival. Entry variables into the multivariate analysis included age, pathological grade, primary tumor stage, lymph node invasion, and metastasis. Age (old age, hazard ratio (HR) 1.230, 95\% confidence interval (CI) 1.107-1.367, using young age as a reference), pathological grade (poor/undifferentiated grade, HR 1.505, 95\% CI 1.292-1.753, using high/moderate grade as a reference), primary tumor stage (late primary tumor stage, HR $1.343,95 \%$ CI 1.205-1.498, using early primary tumor stage as a reference), lymph node status (lymph node invasion, HR 1.177, 95\% CI 1.039-1.335, using no lymph node invasion as a reference), and metastasis (metastasis, HR 1.909, 95\% CI
1.694-2.150, using non-metastatic status as a reference) were independent prognostic factors for ICC (Table 3 ).

Table 3. Multivariate Cox regression model analysis of prognostic factors for cancer specific survival in the primary cohort.

\begin{tabular}{lcll}
\hline Variable & HR & $95 \% \mathrm{CI}$ & P value \\
\hline Age & & & $<0.001$ \\
\hline$<65$ & 1 & Reference & \\
\hline$\geq 65$ & 1.23 & $1.107-1.367$ & \\
\hline Pathological grade & & & $<0.001$ \\
\hline High/moderate & 1 & Reference &
\end{tabular}


the SEER database

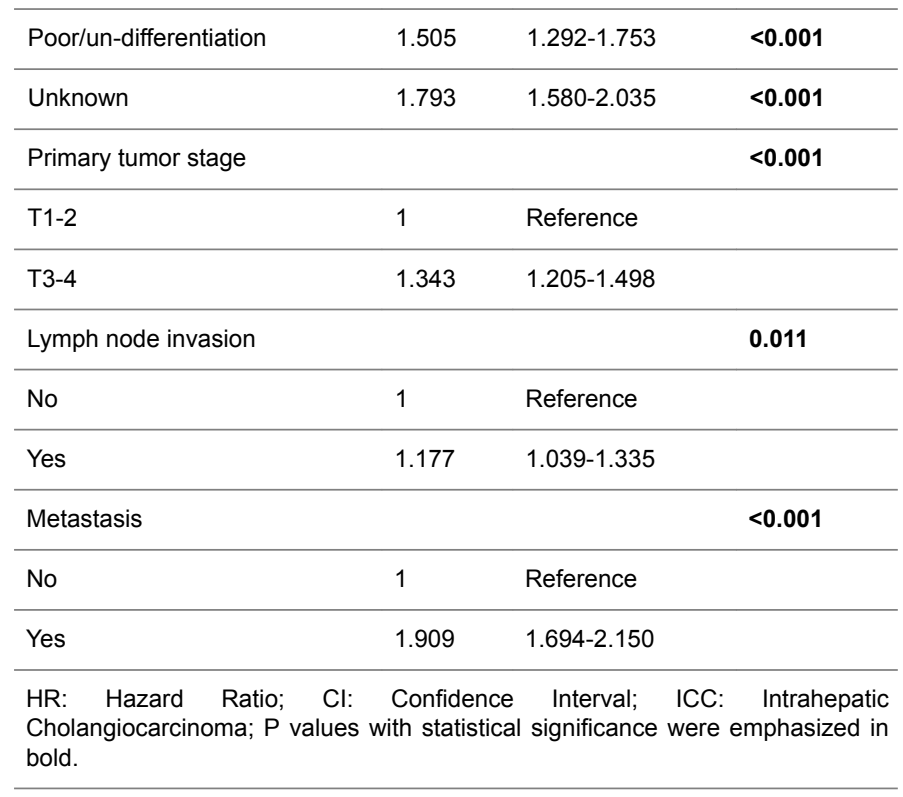

\section{Stratified analysis of effect of age on CSS}

We further analyzed the impact of age on CSS stratified by different races. In Caucasians, elderly patients showed poorer prognosis compared with young patients $(\mathrm{P}=0.011)$. In other races, elderly patients were also associated with poorer survival outcome $(\mathrm{P}=0.036)$. We also analyzed the correlation between age and CSS stratified by different cancer stages. In both the early stage (AJCC stage I or II) and advanced stage (AJCC stage II or IV), elderly patients showed poorer survival $(\mathrm{P}<0.001 ; \mathrm{P}=0.005)$. Additionally, we analyzed the relationship between age and CSS stratified by different therapy methods. In surgical patients, old age were associated with shorter survival time, although not significantly $(\mathrm{P}=0.125)$. In nonoperative patients, old age was a significant prognostic factor $(\mathrm{P}=0.005)$.

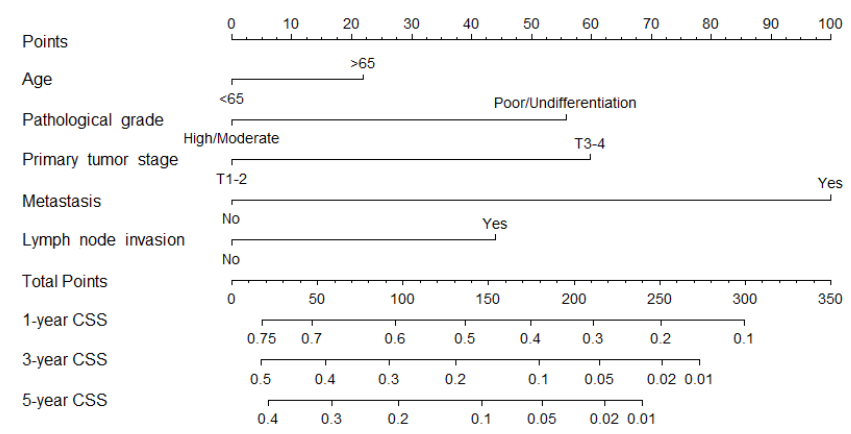

Figure 2. Cancer-specific survival nomogram in ICC patients.

\section{Prognostic nomogram for CSS}

A nomogram that integrated all the independent prognostic factors was established (Figure 2). To use the nomogram, an individual patient's clinicopathological parameters were located on each variable axis, and a line was drawn upward to the "points" axis to determine the score for each variable. The sum of these scores was located on the "total points" axis. A line was drawn downward to determine the likelihood of 1,3 and 5-y CSS.
4

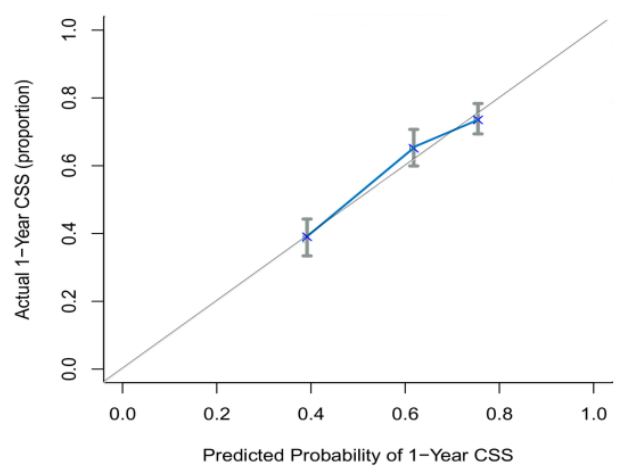

3

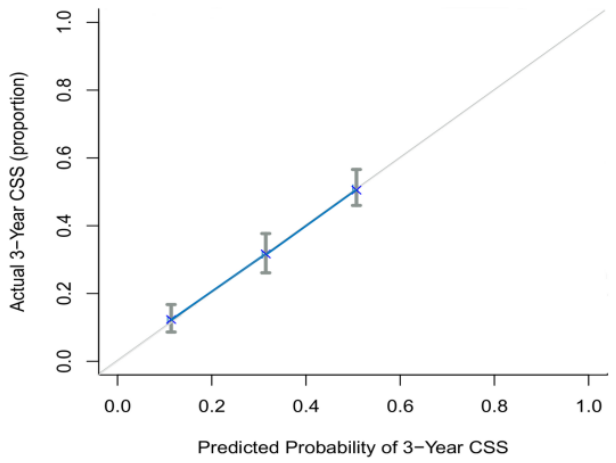

C

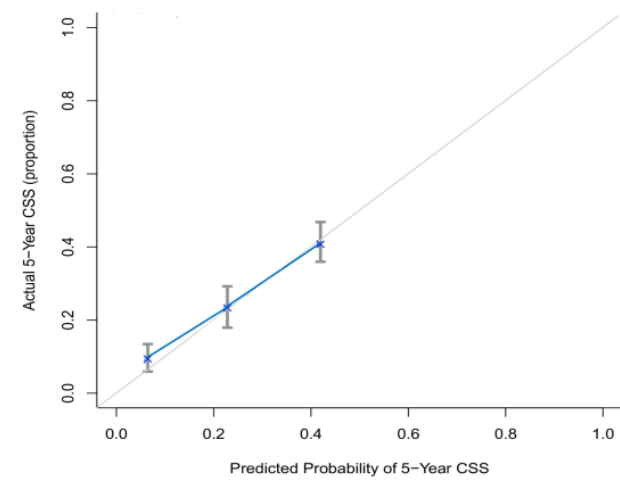

Figure 3. Calibration curves for predicting cancer-specific survival in the primary cohort. A: 1-y CSS; B: 3-y CSS; C: 5-y CSS.

\section{Validation of the predictive accuracy of the nomogram}

The predictive power of the established nomogram and AJCC staging system was compared. In the primary cohort, the Cindex of our nomogram to predict CSS $(0.652,95 \%$ CI $0.630-0.674)$ was higher than that of the conventional AJCC stage $(0.613,95 \%$ CI 0.591-0.635), although this difference was not significant $(\mathrm{P}=0.187)$. The $\mathrm{C}$-index was similar in the validation cohort $(0.655,95 \%$ CI $0.621-0.689)$. Additionally, calibration curves were formulated to assess the performance of the nomogram. The calibration curves in the primary cohort showed optimal agreement between prediction and observation in the probability of 1,3 and 5-y CSS (Figure 3). In the validation cohort, the results also indicated that the nomogrambased prediction was in good agreement with actual observed survival (Figure 4). 
A

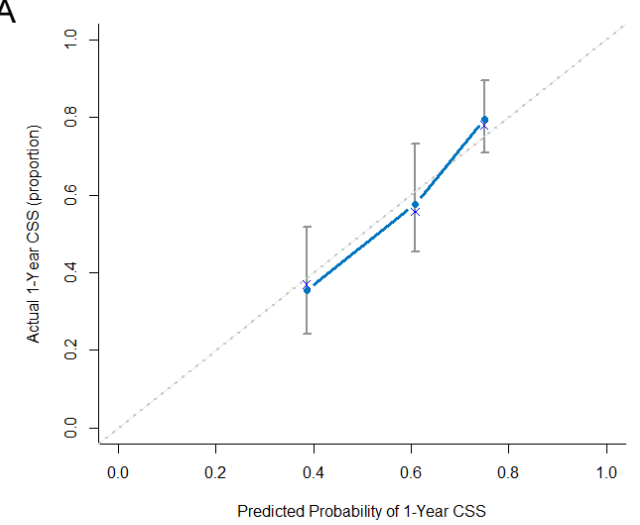

B

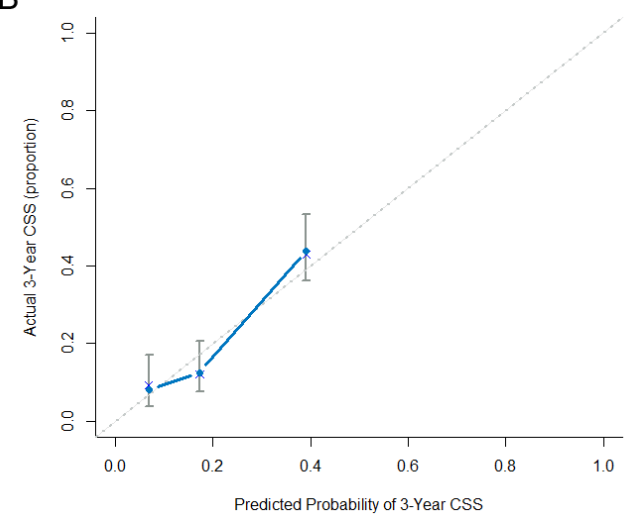

Figure 4. Calibration curves for predicting cancer-specific survival in the validation cohort. A: 1-y CSS; B: 3-y CSS.

\section{Discussion}

The concept that advancing age acts as a critical risk factor for cancer has been increasingly highlighted [22,23]. During aging, multiple mechanisms, both intrinsic (accumulation of DNA damage) and extrinsic (decreases in adaptive immunity; age-related pro-tumorigenic inflammatory microenvironment), converge to drive carcinogenesis [9]. Intriguingly, recent studies have also demonstrated that the aged microenvironment can drive cancer metastasis and therapeutic resistance in preclinical models, raising the possibility that aging is involved in cancer metastasis and that aged cancer patients might have poorer prognosis $[24,25]$. Here, based on the SEER database, we found that aged ICC patients ( $\geq 65 \mathrm{y}$ ) showed poorer shortterm and long-term survival than their younger counterparts, especially among patients who did not undergo surgical treatment. Furthermore, by integrating aging and other independent prognostic factors, we established a novel prognostic nomogram for CSS, which demonstrated superior predictive power than the conventional AJCC staging system.

The dismal outcome following surgical resection of ICC is probably multi-factorial, with loco-regional recurrence being the main cause. For this reason, many recent efforts have been devoted to development of clinically relevant prognostic factors for ICC after curative resection. Currently, tumor number, lymph node metastasis, vascular invasion and high preoperative CA19-9 level are all well-established predictive markers for ICC prognosis after curative resection $[6,17,26]$. However, the prognostic role of aging in ICC after curative resection has remained ambiguous for a long time. Although the prognostic role of aging did not reach statistical significance in several early large cohort studies, it is worth noting that in all of those studies, aging was correlated with better overall survival [6,26-29]. In 2013, results from an international multi-center study and a comprehensive metaanalysis both identified age among the independent clinicopathological parameters predictive of survival after curative resection in ICC [30,31]. Consistently, our study from the SEER database partially supported the prognostic role of old age in ICC patients after curative resection. Considering the small size of the operative group $(n=658)$ compared with the non-operative group $(n=1503)$ in our study, we suggest that other large cohort investigations are still needed to elucidate the prognostic value of aging in ICC patients undergoing curative resection.

Late-stage cases represent a larger percentage of ICC patients who are not amenable to radical resection and have a more dismal outcome, with chemotherapy or radiotherapy being recommended as adjuvant therapy [1]. Intriguingly, in our cohort of non-operative ICC patients, the CSS rates in the elderly group were significantly worse than those in the younger group. Considering the low resectability of ICC, this result is also of clinical relevance, which indicated that the aged non-operative patients were a higher-risk subgroup for cancer progression. All of this evidence points to old age as a bona fide parameter predictive of clinical outcome for ICC after surgical resection and for other therapies.

In light of the emerging role of aging in predicting the CSS of ICC, we support its potential application in optimizing traditional staging models for ICC, such as the AJCC staging system. In recent years, prognostic nomograms were found to be accurate predictive models for cancer patients. Previous prognostic nomograms for ICC were all constructed to predict the OS of ICC after curative resection [6,30,32]. Here, we constructed a novel prognostic nomogram to predict the CSS of all ICC patients irrespective of treatment strategies, which may be helpful for clinical decision-making.

In conclusion, although the prognostic systems for ICC are in a state of evolution with several novel models, our study demonstrated that aging could also provide important prognostic information for ICC patients and further serve as a critical stratification parameter for treatment choice.

\section{Acknowledgement}

This study was supported by Shanghai Sailing Program (No. 17YF1401600) and the NSFC General Program (No. 81672820 , No. 81472677 and No.81672365). The authors acknowledge the efforts of the SEER Program tumor registries in the creation of the SEER database. The contents of this paper are the sole responsibilities of the authors. 


\section{References}

1. Razumilava N, Gores GJ. Cholangiocarcinoma. Lancet 2014; 383: 2168-2179.

2. Moeini A, Sia D, Bardeesy N, Mazzaferro V, Llovet JM. Molecular pathogenesis and targeted therapies for intrahepatic cholangiocarcinoma. Clin Cancer Res 2016; 22: 291-300.

3. Rizvi S, Gores GJ. Pathogenesis, diagnosis, and management of cholangiocarcinoma. Gastroenterology 2013; 145: 1215-1229.

4. Spolverato G, Vitale A, Cucchetti A, Popescu I, Marques HP, Aldrighetti L, Gamblin TC, Maithel SK, Sandroussi C, Bauer TW, Shen F, Poultsides GA, Marsh JW, Pawlik TM. Can hepatic resection provide a long-term cure for patients with intrahepatic cholangiocarcinoma? Cancer 2015; 121: 3998-4006.

5. Spolverato G, Yakoob MY, Kim Y, Alexandrescu S, Marques HP, Lamelas J, Aldrighetti L, Gamblin TC, Maithel SK, Pulitano C, Bauer TW, Shen F, Poultsides GA, Marsh JW, Pawlik TM. The impact of surgical margin status on long-term outcome after resection for intrahepatic cholangiocarcinoma. Ann Surg Oncol 2015; 22: 4020-4028.

6. Wang Y, Li J, Xia Y, Gong R, Wang K, Yan Z, Wan X, Liu G, Wu D, Shi L, Lau W, Wu M, Shen F. Prognostic nomogram for intrahepatic cholangiocarcinoma after partial hepatectomy. J Clin Oncol 2013; 31: 1188-1195.

7. Zhou XD, Tang ZY, Fan J, Zhou J, Wu ZQ, Qin LX, Ma ZC, Sun HC, Qiu SJ, Yu Y, Ren N, Ye QH, Wang L, Ye SL. Intrahepatic cholangiocarcinoma: report of 272 patients compared with 5,829 patients with hepatocellular carcinoma. J Cancer Res Clin Oncol 2009; 135: 1073-1080.

8. Banales JM, Cardinale V, Carpino G, Marzioni M, Andersen JB, Invernizzi P, Lind GE, Folseraas T, Forbes SJ, Fouassier L, Geier A, Calvisi DF, Mertens JC, Trauner M, Benedetti A, Maroni L, Vaquero J, Macias RI, Raggi C, Perugorria MJ, Gaudio E, Boberg KM, Marin JJ, Alvaro D. Expert consensus document: Cholangiocarcinoma: current knowledge and future perspectives consensus statement from the European Network for the Study of Cholangiocarcinoma (ENSCCA). Nat Rev Gastroenterol Hepatol 2016; 13: 261-280.

9. Serrano M. Unraveling the links between cancer and aging. Carcinogenesis 2016; 37: 107.

10. Choi J, Ghoz HM, Peeraphatdit T, Baichoo E, Addissie BD, Harmsen WS, Therneau TM, Olson JE, Chaiteerakij R, Roberts LR. Aspirin use and the risk of cholangiocarcinoma. Hepatology 2016; 64: 785-796.

11. Shaib YH, El-Serag HB, Nooka AK, Thomas M, Brown TD, Patt YZ, Hassan MM. Risk factors for intrahepatic and extrahepatic cholangiocarcinoma: a hospital-based case-control study. Am J Gastroenterol 2007; 102: 1016-1021.

12. Shaib YH, El-Serag HB, Davila JA, Morgan R, McGlynn KA. Risk factors of intrahepatic cholangiocarcinoma in the United States: a case-control study. Gastroenterology 2005; 128: 620-626.

13. Liu RQ, Shen SJ, Hu XF, Liu J, Chen LJ, Li XY. Prognosis of the intrahepatic cholangiocarcinoma after resection: hepatitis $B$ virus infection and adjuvant chemotherapy are favorable prognosis factors. Cancer Cell Int 2013; 13: 99.

14. Chen LP, Li C, Wang C, Wen TF, Yan LN, Li B. Predictive factors of recurrence for patients with intrahepatic cholangiocarcinoma after hepatectomy. Hepatogastroenterology 2012; 59: 1765-1768.

15. Tabrizian P, Jibara G, Hechtman JF, Franssen B, Labow DM, Schwartz ME, Thung SN, Sarpel U. Outcomes following resection of intrahepatic cholangiocarcinoma. HPB (Oxford) 2015; 17: 344-351.

16. Yeh CN, Wang SY, Chen YY, Chen MH, Chiang KC, Cheng CT, Tsai CY, Wang CC, Yeh TS, Chen TC. A prognostic nomogram for overall survival of patients after hepatectomy for intrahepatic cholangiocarcinoma. Anticancer Res 2016; 36: 4249-4258.

17. Spolverato G, Kim Y, Ejaz A, Alexandrescu S, Marques $\mathrm{H}$, Aldrighetti L, Gamblin TC, Pulitano C, Bauer TW, Shen F, Sandroussi C, Poultsides G, Maithel SK, Pawlik TM. Conditional probability of long-term survival after liver resection for intrahepatic cholangiocarcinoma: a multi-institutional analysis of 535 patients. JAMA Surg 2015; 150: 538-545.

18. Zhu HF, Li J, Huang L, Yan YQ. Intrahepatic cholangiocarcinoma: a clinicopathologic study of 37 resected cases. Hepatogastroenterology 2013; 60: 263-267.

19. Harrell FE Jr., Lee KL, Mark DB. Multivariable prognostic models: issues in developing models, evaluating assumptions and adequacy, and measuring and reducing errors. Stat Med 1996; 15: 361-387.

20. Touijer K, Scardino PT. Nomograms for staging, prognosis, and predicting treatment outcomes. Cancer 2009; 115: 3107-3111.

21. Hanley JA, McNeil BJ. A method of comparing the areas under receiver operating characteristic curves derived from the same cases. Radiology 1983; 148: 839-843.

22. Falandry C, Bonnefoy M, Freyer G, Gilson E. Biology of cancer and aging: a complex association with cellular senescence. J Clin Oncol 2014; 32: 2604-2610.

23. Hoeijmakers JH. DNA damage, aging, and cancer. N Engl J Med 2009; 361: 1475-1485.

24. Kaur A, Webster MR, Marchbank K, Behera R, Ndoye A, Kugel CH, 3rd, Dang VM, Appleton J, O'Connell MP, Cheng P, Valiga AA, Morissette R, McDonnell NB, Ferrucci L, Kossenkov AV, Meeth K, Tang HY, Yin X, Wood WH, 3rd, Lehrmann E, Becker KG, Flaherty KT, Frederick DT, Wargo JA, Cooper ZA, Tetzlaff MT, Hudgens C, Aird KM, Zhang R, Xu X, Liu Q, Bartlett E, Karakousis G, Eroglu Z, Lo RS, Chan M, Menzies AM, Long GV, Johnson DB, Sosman J, Schilling B, Schadendorf D, Speicher DW, Bosenberg M, Ribas A, 
Weeraratna AT. sFRP2 in the aged microenvironment drives melanoma metastasis and therapy resistance. Nature 2016; 532: 250-254.

25. Han Z, Brown JR, Niederkorn JY. Growth and metastasis of intraocular tumors in aged mice. Invest Ophthalmol Vis Sci 2016; 57: 2366-2376.

26. Clark CJ, Wood-Wentz CM, Reid-Lombardo KM, Kendrick ML, Huebner M, Que FG. Lymphadenectomy in the staging and treatment of intrahepatic cholangiocarcinoma: a population-based study using the National Cancer Institute SEER database. HPB (Oxford) 2011; 13: 612-620.

27. Tamandl D, Herberger B, Gruenberger B, Puhalla H, Klinger M, Gruenberger T. Influence of hepatic resection margin on recurrence and survival in intrahepatic cholangiocarcinoma. Ann Surg Oncol 2008; 15: 2787-2794.

28. Li T, Qin LX, Zhou J, Sun HC, Qiu SJ, Ye QH, Wang L, Tang ZY, Fan J. Staging, prognostic factors and adjuvant therapy of intrahepatic cholangiocarcinoma after curative resection. Liver Int 2014; 34: 953-960.

29. Bunsiripaiboon P, Sornmayura P, Wilasrusmee C, Lertsithichai P. The prognostic significance of microvessel density in intrahepatic cholangiocarcinoma. J Med Assoc Thai 2010; 93: 66-72.

30. Hyder O, Marques H, Pulitano C, Marsh JW, Alexandrescu S, Bauer TW, Gamblin TC, Sotiropoulos GC, Paul A, Barroso E, Clary BM, Aldrighetti L, Ferrone
CR, Zhu AX, Popescu I, Gigot JF, Mentha G, Feng S, Pawlik TM. A nomogram to predict long-term survival after resection for intrahepatic cholangiocarcinoma: an Eastern and Western experience. JAMA Surg 2014; 149: 432-438.

31. Mavros MN, Economopoulos KP, Alexiou VG, Pawlik TM. Treatment and prognosis for patients with intrahepatic cholangiocarcinoma: systematic review and meta-analysis. JAMA Surg 2014; 149: 565-574.

32. Doussot A, Groot-Koerkamp B, Wiggers JK, Chou J, Gonen M, DeMatteo RP, Allen PJ, Kingham TP, D'Angelica MI, Jarnagin WR. Outcomes after resection of intrahepatic cholangiocarcinoma: external validation and comparison of prognostic models. J Am Coll Surg 2015; 221: 452-461.

\section{*Correspondence to}

Zheng Wang

Department of General Surgery

Institute of Cancer Metastasis

Huashan Hospital

Fudan University

Shanghai

China 